\title{
Correction to: Nancy L. Segal and Yesika S. Montoya: Accidental Brothers: The Story of Twins Exchanged at Birth and the Power of Nature and Nurture
}

\section{St Martin's Press, New York, 2018, 325 pp, ISBN: 9781250101907}

Jeffrey M. Craig ${ }^{1,2}$

Published online: 28 August 2018

○ Springer Science+Business Media, LLC, part of Springer Nature 2018

\section{Correction to: Behavior Genetics} https://doi.org/10.1007/s10519-018-9917-z

The original version of this article unfortunately contained a mistake. The family name of the author in the title was misspelled as Yesika S. Monto instead of Yesika S. Montoya. The author name is corrected with this erratum.

The original article can be found online at https://doi.org/10.1007/ s10519-018-9917-z.

\section{Jeffrey M. Craig}

Jeffrey.craig@deakin.edu.au

1 Centre for Molecular and Medical Research, School of Medicine, Deakin University, Geelong, VIC 3220, Australia

2 Environmental \& Genetic Epidemiology Research, Murdoch Children's Research Institute, Royal Children's Hospital, Parkville, VIC 3052, Australia 